\title{
Rectal Fissure, CTCAE
}

National Cancer Institute

\section{Source}

National Cancer Institute. Rectal Fissure, CT CAE. NCI Thesaurus. Code C143200.

A disorder characterized by a tear in the lining of the rectum. 